\title{
Fertility in Patients with Congenital Adrenal Hyperplasia
}

\author{
H.L. Claahsen-van der Grinten', N.M.M.L. Stikkelbroeck, ${ }^{1,2}$, C.G.J. Sweep ${ }^{3}$, \\ A.R.M.M. Hermus ${ }^{2}$ and B.J. Otten ${ }^{1}$ \\ ${ }^{\prime}$ Department of Paediatric Endocrinology, ${ }^{2}$ Department of Endocrinology and \\ ${ }^{3}$ Department of Chemical Endocrinology, Radboud University Nijmegen Medical Centre, \\ Nijmegen, The Netherlands
}

\begin{abstract}
Congenital adrenal hyperplasia (CAH) is generally regarded as a paediatric endocrine disease, but nowadays nearly all patients reach adulthood as a result of improved diagnosis and treatment. It is now increasingly recognised that treatment goals shift during life: one of the major treatment goals in childhood and puberty, i.e. normal growth and development, is no longer relevant after childhood, whereas other aspects, such as fertility and side effects of longterm glucocorticoid treatment, become more important in adulthood. This paper focuses on fertility in male and female adult patients with CAH. In males with $\mathrm{CAH}$ the fertility rate is reduced compared with the normal population, the most frequent cause being testicular adrenal rest tumours. Development and growth of these tumours is assumed to be ACTH dependent and undertreatment may play an important role. If intensifying glucocorticoid treatment does not lead to tumour decrease, surgical intervention may be considered, but the effect on fertility is not yet known. In females with CAH the degree of fertility depends on the phenotype of the CAH. Most fertility problems are seen in the classic salt-wasting type. Age of menarche and regularity of the menstrual cycle depends on the degree of adrenal suppression. Not only adrenal androgens have to be normalised but also the levels of adrenal progestins (progesterone and
\end{abstract}

Reprint address:

B.J. Otten, M.D., Ph.D.

Radboud University Nijmegen Medical Centre

Department of Paediatric Endocrinology (833)

P.O. Box 9101

6500 HB Nijmegen, The Netherlands

e-mail: B.Otten@cukz.umcn.nl

VOLUME 19, NO. 5, 2006
17-OH-progesterone) that interfere with normal ovulatory cycles. The regularity of menstrual cycles can be considered as an important measure of therapeutic control in adolescent females with CAH and therefore as a therapeutic goal from (peri)pubertal years on. Other factors that contribute to impaired fertility in females with CAH are ovarian hyperandrogenism (polycystic ovary syndrome), ovarian adrenal rest tumours, genital surgery and psychological factors. Subfertility in CAH can have its origin already in the peripubertal years and is therefore of interest to the paediatric endocrinologist.

\section{KEY WORDS}

congenital adrenal hyperplasia, fertility

\section{INTRODUCTION}

Congenital adrenal hyperplasia $(\mathrm{CAH})$ is a disorder of adrenal steroid synthesis. In $95 \%$ of cases, it is caused by 21-hydroxylase deficiency, leading to cortisol deficiency and (in most cases) aldosterone deficiency. The compensatory increase in adrenocorticotropin (ACTH) secretion by the pituitary gland leads to stimulation of the adrenals and, consequently, overproduction of androgens. The phenotype of 21-hydroxylase deficiency depends on the degree of enzyme deficiency. Complete 21 hydroxylase deficiency leads to the classic saltwasting form with congenital virilization in females. Less severe 21-hydroxylase deficiency results in the classic simple virilizing form without aldosterone deficiency. Patients with the mildest form, the late onset form of $\mathrm{CAH}$, present with symptoms caused by androgen excess only: pseudoprecocious puberty, hirsutism, menstrual irregularities and infertility ${ }^{1}$. 
Treatment of 21-hydroxylase deficiency consists of glucocorticoid supplementation and in case of aldosterone deficiency also mineralocorticoid supplementation.

In the past, $\mathrm{CAH}$ was generally regarded as a paediatric endocrine disease, but nowadays nearly all patients reach adulthood as a result of improved diagnosis and treatment. Thus, the spectrum of $\mathrm{CAH}$ as a lifelong chronic disease becomes gradually clear, and it is increasingly recognised that treatment goals shift during life: the major treatment goals in childhood and puberty, i.e. normal growth and development, are no longer relevant after childhood, whereas other aspects, such as fertility and the side effects of long-term glucocorticoid treatment, become more important in adulthood. In this paper we focus on fertility in adult male and female patients with $\mathrm{CAH}$.

\section{FERTILITY IN MALE PATIENTS WITH CONGENITAL ADRENAL HYPERPLASIA}

There is evidence that fertility is impaired in males with $\mathrm{CAH}$. Jääskeläinen et al. found a significantly lower child rate $(0.07)$ in 16 male patients with $\mathrm{CAH}$ compared with an age matched Finnish male control group $(0.34)^{2}$. Other studies report child rate only as additional information in selected patient populations ${ }^{3-5}$. An alternative method to investigate fertility in men is semen analysis. Wuesthof et al. reported normal semen analysis in only $34 \%$ of 53 males with $\mathrm{CAH}^{4}$. Cabrera et al. reported abnormal semen analysis in $46 \%$ of 16 investigated patients ${ }^{5}$. In our own series, only four of 11 men with CAH had a normal sperm count ${ }^{6}$. However, not all patients are willing to collect semen for analysis. Measurement of serum follicle stimulating hormone (FSH) and inhibin B levels is also used to assess fertility in men with $\mathrm{CAH}$. Several studies report abnormal FSH levels,

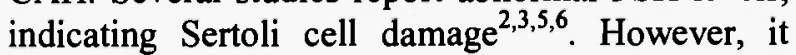
should be noted that in $\mathrm{CAH}$ patients with primary testicular damage, serum gonadotropin levels might be suppressed due to high levels of adrenal androgens. Most of these patients also have serum testosterone levels within the normal range, which is the result of conversion of adrenal androgens to testosterone. In this situation a more reliable predictor of testicular damage is the serum inhibin B level, which reflects Sertoli cell function.

The most important cause of infertility in men with $\mathrm{CAH}$ is the presence of testicular tumours resulting in primary gonadal failure. Another important factor contributing to infertility is the suppression of the hypothalamic-pituitary-gonadal axis due to high circulating levels of androgens resulting in secondary gonadal failure.

\section{Testicular adrenal rest tumours}

Testicular tumours in male patients with $\mathrm{CAH}$ are thought to arise from aberrant adrenal cells in the testes that are stimulated by $\mathrm{ACTH}^{7}$. Therefore they are called testicular adrenal rest tumours. Testicular adrenal rest tumours have also been described in other conditions with high plasma ACTH levels, such as Nelson's syndrome or Addison's disease ${ }^{8,9}$. However, testicular tumours are also found in well-controlled patients with $\mathrm{CAH}$, with normal or suppressed $\mathrm{ACTH}{ }^{5,6}$. The reported prevalence of testicular adrenal rest tumours in males varies between $0 \%$ and $94 \%$, depending on the selection of the patients and the method of detection ${ }^{2,3,5,6,10,11}$. In our own series, one or more testicular tumours were found in 16 of 17 patients (age 16-40 years). Ultrasound seems to be the best method for detection and follow up, especially in the case of small non-palpable tumours $^{12}$. Testicular tumours have also been reported in patients under the age of 16 years ${ }^{10,13,14}$. We now routinely follow our male children with $\mathrm{CAH}$ ( $\mathrm{n}=25$; age 6-19 years) with ultrasound and detected seven boys with small, mostly nonpalpable tumours, the youngest patient being 7 years old (unpublished data). The testicular tumours, which are always located in the mediastinum testis, can lead to obstruction of the vascular supply and compression and atrophy of the seminiferous tubules. In addition to these mechanical effects, steroids produced by the tumours could be toxic to testicular tissue (paracrine effect) therefore contributing to testicular failure ${ }^{15}$. These two factors result in primary gonadal failure with elevated gonadotropin levels and low inhibin B levels. Therefore treatment or prevention of the development of testicular tumours is an important goal. 
Poor hormonal control with inadequate suppression of ACTH may be a main factor in the aetiology of testicular tumours ${ }^{16-18}$. By increasing the glucocorticoid dose, ACTH secretion is suppressed and the adrenal rest tissue is no longer stimulated, which may lead to testicular tumour shrinkage. The need for tumour shrinkage and the side effects of increasing glucocorticoid therapy must be carefully balanced, especially in asymptomatic patients ${ }^{19}$. The effect of medical treatment is described mostly in case reports or in small patient groups and the results vary dependent on patient selection, type of $\mathrm{CAH}$ and treatment choice ${ }^{14,20-24}$. Rutgers et al. reported tumour shrinkage in $75 \%$ of 16 patients after increasing the glucocorticoid dose ${ }^{21}$. Walker et al. reviewed 75 cases of testicular tumours in $\mathrm{CAH}$ and stated that the majority of the masses regressed with an increase in glucocorticoid dose $\mathrm{e}^{22}$. Rich et al. reported testicular tumours in three young patients $(5,15$ and 17 years old). Intensifying the glucocorticoid therapy resulted in normalising the elevated steroid levels in all patients. However, in no case were the tumours resolved, and there was partial regression in only one patient ${ }^{14}$. In our own study population we also found unpredictable results ${ }^{23}$ : tumour decrease was found in six of the 15 male patients with $\mathrm{CAH}$ after intensifying glucocorticoid therapy, but tumour decrease was also seen in one patient with undertreatment. Tumour increase was also seen in patients with adequate treatment. Use of dexamethasone instead of hydrocortisone in the night resulted in better adrenal suppression in only one of our patients. Therefore general guidelines for glucocorticoid strategies cannot been given, and the decision for dose and timing of glucocorticoid treatment has to be made individually in all patients, with special attention to side effects.

If tumour size does not decrease with increasing glucocorticoid therapy or if there is persistent azoospermia despite tumour shrinkage, surgical intervention may be considered ${ }^{22,25}$. In the past orchiectomy was performed. However the malignant potential of these tumours is negligible ${ }^{26}$. Walker $e t$ al. performed testis sparing surgery in three patients with $\mathrm{CAH}^{22}$. Postoperatively there was good vascular flow and no recurrence of the tumour. However investigations to assess fertility were not performed. Tiryaki et al. reported two male $\mathrm{CAH}$ patients with steroid unresponsive testicular tumours who were also treated by testis sparing tumour enucleation ${ }^{25}$. Again no data about fertility before and after operation were reported. Because fertility prognosis in $\mathrm{CAH}$ males with testicular tumours remains uncertain, cryopreservation of semen could be proposed to young adult male patients. In case of unwanted infertility, assisted reproduction could be considered. When there is obstructive azoospermia, testicular aspiration and intracytoplasmatic sperm injection may offer a solution $^{15}$. At least in some cases deterioration of fertility by testicular tumour growth can be prevented by early increase of glucocorticoid therapy. Furthermore, early testis sparing surgery as soon as testicular tumours are detected has the potential to prevent damage to the testicular tissue. Therefore it may be that detection of the tumours by ultrasonography at an early stage (prepubertal) is useful. However, further investigations are necessary to support this hypothesis.

\section{Hypogonadotropic hypogonadism}

In poorly controlled patients with $\mathrm{CAH}$ the elevated ACTH levels induce high levels of androstenedione, which is partly aromatised to oestron. These high levels of androgens and oestron will suppress the hypothalamic-pituitary-gonadal axis, leading to hypogonadotropic hypogonadism and small testes ${ }^{17,18.27}$. It may be that steroids produced by testicular adrenal rest tumours contribute to the suppression of the hypothalamic-pituitary-gonadal axis. However this effect cannot be separated from the effects resulting from adrenal androgen excess.

Hypogonadotropic hypogonadism may also occur in males with previously undiagnosed late onset 21-hydroxylase deficiency. In this condition adrenal rest tumours are not a common finding. Most reports show reversible hypogonadism and improved fertility after initiating or increasing glucocorticoid therapy ${ }^{28,29}$. 


\section{FERTILITY IN WOMEN WITH CONGENITAL ADRENAL HYPERPLASIA}

In women with $\mathrm{CAH}$ due to 21 -hydroxylase deficiency, fertility seems to be reduced, based on reports of decreased pregnancy rates, decreased live-birth rates and menstrual disorders ${ }^{30,31}$.

Most reports about pregnancies in female patients with classic 21-hydroxylase deficiency are case studies. There are only a few reports providing pregnancy rates or live-birth rates in large populations of patients with $\mathrm{CAH}^{32-36}$ : the live-birth rate in patients with classic salt-wasting $\mathrm{CAH}$ is $0-10 \%$ $(\mathrm{n}=64)$, in simple virilizing patients $33-50 \%(\mathrm{n}=$ 83) and in non-classic patients $63-90 \%(n=18)$. In the general population or in age-matched controls, pregnancy rates or live-birth rates are $65-91 \%^{32-35}$. Thus, compared with a non-CAH female population, pregnancy and live-birth rates are severely reduced in patients with salt-wasting $\mathrm{CAH}$, mildly reduced in patients with simple virilizing $\mathrm{CAH}$, and normal in patients with non-classic CAH. Pregnancy outcomes in women with classic $\mathrm{CAH}$ have been reviewed by Lo and Grumbach ${ }^{37}$. They found 105 reported pregnancies in 73 women with $\mathrm{CAH}$ (20 salt-wasting patients, 53 simple virilizing patients), resulting in 74 live-born children. Of these 105 pregnancies, $11(10 \%)$ led to spontaneous abortion and $11(10 \%)$ were electively terminated.

Data on fertility in patients with non-classic 21 hydroxylase deficiency are predominantly derived from studies in patients in whom the diagnosis of $\mathrm{CAH}$ was made after they had presented with subfertility and/or other symptoms of hyperandrogenism. As a result, these fertility data represent only the symptomatic subset of the non-classic $\mathrm{CAH}$ population, and this introduces substantial bias. It has become clear that the prevalence of nonclassic $\mathrm{CAH}$ is relatively high, but when the disease is mild, patients may never come to clinical presentation. In two reports on fertility in nonclassic patients presenting with subfertility, the corrected pregnancy rate was $93 \%$ and $100 \%^{38.39}$, spontaneously or after glucocorticoid treatment (with or without clomiphene citrate).

Instead of pregnancy rates and live-birth rates as direct markers of fertility, regularity of menstrual cycles can be used as an indirect marker of fertility, particularly in adolescent girls. In most reports, a normal mean age of menarche was observed in girls with $\mathrm{CAH}^{40-42}$, but these data are misleading because by definition only the patients who did experience menarche were included. In women with $\mathrm{CAH}$, delayed menarche can be associated with poor therapeutic control. Menstrual irregularity in women with $\mathrm{CAH}$ has also been associated with poor therapeutic control ${ }^{41}$ and in non-classical $\mathrm{CAH}$, menstrual irregularity is typically one of the presenting signs.

Several factors have been suggested to contribute to impaired fertility in females with $\mathrm{CAH}$ : adrenal overproduction of androgens and progestins (17-hydroxyprogesterone and progesterone), ovarian hyperandrogenism (polycystic ovary syndrome), ovarian adrenal rest tumours, genital surgery, and psychological factors such as delayed psychosexual development, reduced sexual activity and low maternal feelings.

\section{Adrenal overproduction of androgens and progestins}

Androgen overproduction by the adrenal gland can directly and indirectly affect ovarian activity. Directly, androgen excess inhibits ovarian folliculogenesis. The hypothesis that androgen excess has a negative (direct and/or indirect) effect on ovulation is supported by the finding that suppression of adrenal androgen secretion by increasing the glucocorticoid dose can restore ovulation in patients with $\mathrm{CAH}$. However, in some patients adequate suppression of androgen levels was not sufficient to correct menstrual abnormalities. In these patients, increased levels of progestins (progesterone and 17hydroxyprogesterone) as a result of adrenal overproduction interfered with normal menstrual cycles $^{34,41,43,44}$.

Elevated progestin levels may cause persistent inhibition of follicular growth, inhibition of endometrial proliferation and failure of endometrial breakdown, resulting in menstrual disorders. In addition, even if regular ovulation and menstruation is achieved, elevated progesterone levels from adrenal origin can still prevent conception in women with $\mathrm{CAH}$, by causing involution of the endometrium and impermeability of the cervical mucus $^{45}$. 
Thus, adequate suppression of adrenal androgens and progestins is needed for menarche and regular menstrual cycles. In reverse, the regularity of menstrual cycles can be considered as a measure of therapeutic control in females with $\mathrm{CAH}$ and should be aimed at from pubertal years on.

\section{Hypogonadotropic hypogonadism}

Similar to male patients with $\mathrm{CAH}$, oversecretion of androgens, which are mostly aromatized to oestron, can result in hypogonadotropism, contributing to anovulation or dysovulation. Adequate suppression of androgens can help to restore gonadotrophin cyclicity and therefore regular menstrual cycles. However, in contrast to the experience in male patients with $\mathrm{CAH}$, these findings are rare in female patients ${ }^{46,47}$.

\section{Polycystic ovarian syndrome (PCOS)}

PCOS is characterized by ovulatory dysfunction and hyperandrogenism with irregular menstrual cycles, hirsutism and acne, leading to subfertility. In the classic form polycystic ovaries are detected. The pathogenesis of PCOS is still uncertain but there is evidence that the androgens result from ovarian overproduction $^{48}$. Female patients with $\mathrm{CAH}$ with poor hormonal control as well as untreated women with the non-classic form of $\mathrm{CAH}$ can have a similar clinical presentation, including sonographic evidence of ovarian cysts resulting from adrenal hyperandrogenism. In both conditions significantly elevated levels of androgens, 17hydroxyprogestrone and insulin insensitivity have been described ${ }^{49-52}$. So the distinction between these two conditions can be difficult. Differentiation can be made upon post-ACTH rise in 17hydroxyprogestrone and molecular analysis ${ }^{52,52}$. Because PCOS is associated with reduced fertility ${ }^{54}$ it is suggested that the presence of PCOS in patients with $\mathrm{CAH}$ can be an additional factor in the mechanism of subfertility in women with $\mathrm{CAH}^{1,55}$. Stikkelbroeck et al. investigated the prevalence of PCOS in 13 female patients with $\mathrm{CAH}$. Polycystic ovaries were found in two patients $(15.4 \%)$ reflecting a prevalence corresponding to the general population ${ }^{56}$. Therefore it is unlikely that PCOS is a frequent cause of infertility in women with $\mathrm{CAH}$.

\section{Ovarian adrenal rest tumours}

In contrast to the high prevalence of testicular tumours in male patients with $\mathrm{CAH}$, ovarian adrenal rest tumours have been described only in case reports $^{57-59}$. In our own study of 13 women with $\mathrm{CAH}$, no ovarian adrenal rest tumours could be detected either by ultrasonography or by magnetic resonance imaging (MRI), which suggests that ovarian adrenal tumours are rare and do not frequently contribute to female subfertility ${ }^{56}$. Therefore routine ovarian imaging in these patients is not indicated.

\section{Genital surgery}

Besides the endocrine factors described above, the effects of genital surgery in early life also play an important role in impaired fertility in women with $\mathrm{CAH}$. Surgical reconstruction of ambiguous genitalia in $46, \mathrm{XX}$ neonates consists of reduction of clitoral size, creation of labia minora and exteriorisation of the vagina, thereby creating a functional vagina to allow menstruation and sexual activity ${ }^{60,61}$. The most important factors related to surgery that can interfere with sexual disturbance are loss of clitoral sensitivity, intravaginal stenosis and disturbed vaginal arousal ${ }^{62}$. In the past in female neonates with clitoromegaly, clitoridectomy was performed with loss of sensitivity due to damage to the neurovascular supply. Currently the preferred technique is clitoroplasty with excision of the erectile tissue preserving the neurovascular supply to the glans ${ }^{63}$. However, recent data show that there is still abnormal clitoral sensation even after optimising the surgical technique ${ }^{62}$. The incidence of vaginal stenosis after surgery varies dependent on the type of operation ${ }^{64,65}$. In the past stenosis was reported in up to $77 \%{ }^{81}$. Krege et al. reported vaginal stenosis in $36 \%$ of patients, with a requirement for additional treatment (manual dilatation, secondary vaginoplasty) ${ }^{66}$. Therefore modern surgical techniques performed by experienced surgeons can improve the functional results of the surgery. 


\section{Psychosexual factors}

Several studies show gender atypical behaviour in female patients with $\mathrm{CAH}^{67-75}$. It is suggested that biological and social factors contribute to the development of gender identity disorders in these patients. Pre- and postnatal exposure to androgens can cause gender atypical behaviour resulting in more boyish behaviour, such as preference for male typical toys and admiration for male characters. Furthermore, significantly less satisfaction with the female sex of assignment is reported ${ }^{\text {śt. }}$. However, social factors can also influence the development of gender identity, such as inability of parents to accept the sex assignment ${ }^{67}$. These gender identity disorders can contribute to subfertility in female patients with $\mathrm{CAH}^{69}$. There is controversy about the rate of bisexuality or homosexuality. Other psychosocial factors can be anxiety about sexual activity and inability to achieve orgasm.

\section{CONCLUSION}

Congenital adrenal hyperplasia and its treatment have a considerable impact on fertility in both males and females. It is important to recognize that the majority of causes impairing fertility are already present in childhood, and therefore should be a treatment goal already in (peri)pubertal years. $\mathrm{CAH}$ should therefore be regarded as a lifelong disease: the implications of $\mathrm{CAH}$ and its treatment reach beyond childhood.

\section{REFERENCES}

1. White PC, Speiser PW. Congenital adrenal hyperplasia due to 21-hydroxylase deficiency. Endocr Rev 2000; 21: 245-291.

2. Jaaskelainen J, Kiekara O, Hippelainen M, Voutilainen $R$. Pituitary gonadal axis and child rate in males with classical 21-hydroxylase deficiency. J Endocrinol Invest 2000; 23: 23-27.

3. Urban MD, Lee PA, Migeon CJ. Adult height and fertility in men with congenital virilizing adrenal hyperplasia. N Engl J Med 1978; 299: 1392-1396.

4. Wuesthof AR, Willig RP, Schulze W, Hoepffiner W, Knorr D, Schwarz HP. Spermatogenesis is impaired in men with congenital adrenal hyperplasia. Horm Res 1998; 50: 104-104.
5. Cabrera MS, Vogiatzi MG, New MI. Long term outcome in adult males with classic congenital adrenal hyperplasia. J Clin Endocrinol Metab 2001; 86: 3070-3078.

6. Stikkelbroeck NMML, Otten BJ, Pasic A, Jager GJ, Sweep CGJ, Noordam K, Hermus ARMM. High prevalence of testicular adrenal rest tumours, impaired spermatogenesis, and Leydig cell failure in adolescent and adult males with congenital adrenal hyperplasia. J Clin Endocrinol Metab 2001; 86: 5721-5728.

7. Clark RV, Albertson BD, Munabi A, Cassorla F, Aguilera G, Warren DW, Sherins RJ, Loriaux DL. Steroidogenic enzyme activities, morphology and receptor studies of a testicular adrenal rest in a patient with congenital adrenal hyperplasia. J Clin Endocrinol Metab 1990; 70: 1408-1413.

8. Johnson RE, Scheithauer B. Massive hyperplasia of testicular adrenal rests in a patient with Nelson's syndrome. Am J Pathol 1982; 77: 501-507.

9. Seidenwurm D, Smathers RL, Kan P, Hoffman A Intratesticular adrenal rests diagnosed by ultrasound. Radiology 2004; 14: 1802-1806.

10. Avila NA, Premkumar A, Shawker TH, Jones JV, Laue L, Cutler GB. Testicular adrenal rest tissue in congenital adrenal hyperplasia: Findings at gray-scale and colour Doppler US. Radiology 1996; 198: 99-104.

11. Avila NA, Premkumar A, Merke DP. Testicular adrenal rest tissue in congenital adrenal hyperplasia: comparison of MR imaging and sonographic findings. Am J Roentgenol 1999; 172: 1003-1006.

12. Stikkelbroeck NMML, Suliman HM, Otten BJ, Hermus ARMM, Blickman $J_{2}$ Jager GJ. Testicular adrenal rest tumours in postpubertal males with congenital adrenal hyperplasia: sonographic and MR features. Eur Radiol 2003; 13: 1603.

13. Shanklin DR, Richardson AP Jr, Rothstein G. Testicular hilar nodules in adrenogenital syndrome. Am J Dis Child 1963; 106: 243-250.

14. Rich MA, Keating MA, Levin HS, Kay R. Tumours of the adrenogenital syndrome: an aggressive conservative approach. J Urol 1998; 160: 1838-1841.

15. Murphy H, George C, de Kretser DD, Judd S. Successful treatment with ICSI of infertility caused by azoospermia associated with adrenal rests in the testes: case report. Hum Reprod 2001; 16: 263-267.

16. Otten BJ, Stikkelbroeck MML, Hermus ARMM. Hypogonadism in males with congenital adrenal hyperplasia. In: Winters SJ, ed. Male Hypogonadism: Basic, Clinical and Therapeutic Principles. Totowa, NJ: Humana Press, 2004; $125-137$.

17. Moore GW, Lacroix A, Rabin D, McKenna TJ. Gonadal dysfunction in adult men with congenital adrenal hyperplasia. Acta Endocrinol (Copenh) 1980; 95: 185-193.

18. Bonaccorsi AC, Adler I, Figueiredo JG. Male infertility due to congenital adrenal hyperplasia: testicular biopsy findings, hormonal evaluation, and therapeutic results in three patients. Fertil Steril 1987; 47: 664-670. 
19. Merke DP, Bornstein SR, Avila NA, Chrousos GP. NIH conference. Future directions in the study and management of congenital adrenal hyperplasia due to 21hydroxylase deficiency. Ann Intern Med 2002; 136: 320334.

20. Giacaglia LR, Mendonca BB, Madureira G, Melo KFF, Suslik CA, Arnhold IJP, Bacheca ASS. Adrenal nodules in patients with congenital adrenal hyperplasia due to 21-hydroxylase deficiency: regression after adequate hormonal control. J Pediatr Endocrinol Metab 2001; 14: 415-419.

21. Rutgers JL, Young RH, Scully RE. The testicular tumour of the adrenogenital syndrome. A report of six cases and review of the literature on testicular masses in patients with adrenocortical disorders. Am J Surg Pathol 1988; 12: 503-513.

22. Walker BR, Skoog SJ, Winslow BH, Canning DA, Tank ES. Testis sparing surgery for steroid unresponsive testicular tumours of the adrenogenital syndrome. J Urol 1997; 157: 1460-1463.

23. Stikkelbroeck NML, Hermus ARMM, Suliman HM, Jager GJ, Otten BJ. Asymptomatic testicular adrenal rest tumours in adolescent and adult males with congenital adrenal hyperplasia: basal and follow-up investigation after 2.6 years. J Pediatr Endocrinol Metab 2004; 17: 645-653.

24. Battaglia M, Di Tonno P, Palazzo S, Bettocchi C, Selvaggio O, Garofano L, Selvaggi FP. Bilateral tumours of the testis in 21 hydroxylase deficiency without adrenal hyperplasia. Urol Oncol 2005; 23: 178180.

25. Tiryaki T, Aycan Z, Huecumenglu $S$. Testis sparing surgery for steroid unresponsive testicular tumors of the congenital adrenal hyperplasia. Pediatr Surg Int 2005; 21: 853-855.

26. Davis JM, Woodroof J, Sadasivan R, Stephens R. Case report: congenital adrenal hyperplasia and malignant Leydig cell tumour. Am J Med Sci 1995; 309: 63-65.

27. Molitor JT, Chertow BS, Fariss BL. Long-term followup of a patient with congenital adrenal hyperplasia and failure of testicular development. Fertil Steril 1973; 24: 319-323.

28. Títinen A, Valimaki M. Primary infertility in a 45-year old man with untreated 21-hydroxylase deficiency: successful outcome with glucocorticoid therapy. J Clin Endocrinol Metab 2002; 87: 2442-2445.

29. Kalachanis I, Rousso D, Kourtis A, Goutzioulis F, Makedos G, Panidis D. Reversible infertility, pharmaceutical and spontaneous, in a male with late onset congenital adrenal hyperplasia, due to 21-hydroxylase deficiency. Arch Androl 2002; 48: 37-41.

30. Stikkelbroeck NMML, Hermus ARMM, Braat DDM, Otten BJ. Fertility in women with congenital adrenal hyperplasia due to 21-hydroxylase deficiency. Obstet Gynaecol Surv 2003; 58: 275-284.

31. Dumic $M$, Janjanin $N$, Ille J, Zunec $R$, Spehar A, Zlopasa G, Francetic I, New MI. Pregnancy outcomes in women with classical adrenal hyperplasia due to 21hydroxylase deficiency. J Pediatr Endocrinol Metab 2005; 18: 887-895.

32. Mulaikal RM, Migeon CJ, Rock JA. Fertility rates in female patients with congenital adrenal hyperplasia due to 21-hydroxylase deficiency. N Engl J Med 1987; 316 : 178-182.

33. Hoepffner W, Schulze E, Bennek J, Keller E, Ewillgerodt $H$. Pregnancies in patients with congenital adrenal hyperplasia with complete or almost complete impairment of 21-hydroxylase deficiency. Fertil Steril 2004; 81: 1314-1320.

34. Helleday J, Siwers B, Ritzen EM, Carlstrom K. Subnormal androgen and elevated progesterone levels in women treated for congenital virilizing 21-hydroxylase deficiency. J Clin Endocrinol Metab 1993; 76: 933-936.

35. Jaaskelainen J, Hippelainen M, Kiekara O, Voutilainen $R$. Child rate, pregnancy outcome and ovarian function in females with classical 21-hydroxylase deficiency. Acta Obstet Gynecol Scand 2000; 79: 687-692.

36. Krone N, Wachter I, Stefanidou M, Roscher AA, Schwarz HP. Mothers with congenital adrenal hyperplasia and their children: outcome of pregnancy, birth and childhood. Clin Endocrinol (Oxf) 2001; 55: 523529.

37. Lo JC, Grumbach MM. Pregnancy outcomes in women with congenital virilizing adrenal hyperplasia. Endocrinol Metab Clin North Am 2001; 30: 207-229, IX.

38. Fitness J, Dixit N, Webster D, Torresani T, Pergolizzi R, Speiser PW, Day DJ. Genotyping of CYP21, linked chromosome $6 \mathrm{p}$ markers, and a sex-specific gene in neonatal screening for congenital adrenal hyperplasia. J Clin Endocrinol Metab 1999; 84: 960-966.

39. Birnbaum MD, Rose LI. Late onset adrenocortical hydroxylase deficiency associated with menstrual dysfunction. Obstet Gynecol 1984; 63: 445-451.

40. Feldman S, Billaud L, Thalabard JC, Raux-Demay MC, Mowszowicz I, Kuttenn F, Mauvais-Jarvis P. Fertility in women with late-onset adrenal hyperplasia due to 21hydroxylase deficiency. J Clin Endocrinol Metab 1992; 74: 635-639.

41. Holmes-Walker DJ, Conway GS, Honour JW. Menstrual disturbance and hypersecretion of progesterone in women with congenital adrenal hyperplasia due to 21hydroxylase deficiency. Clin Endocrinol (Oxf) 1995; 43: 291-296.

42. Hagenfeldt K, Ritzen EM, Ringertz H, Helleday J, Carlstrom K. Bone mass and body composition of adult women with congenital virilizing 21-hydroxylase deficiency after glucocorticoid treatment since infancy. Eur J Endocrinol 2000; 143: 667-671.

43. Rosenfield RL, Bickel S, Razdan AK Amenorrhea related to progestin excess in congenital adrenal hyperplasia. Obstet Gynecol 1980; 56: 208-215.

44. Riad-Fahmy D, Read GF, Walker RF, Griffithset K. Steroids in saliva for assessing endocrine function. Endocr Rev 1982; 3: 367-395. 
45. Speroff L, Glass RH, Kase NG, eds. Clinical Gynecologic Endocrinology and Infertility, $6^{\text {th }}$ Ed. Maryland: Lippincott Williams \& Wilkins, 1999.

46. Richards GE, Grumbach MM, Kaplan SL, Conte FA. The effect of long acting glucocorticoids on menstrual abnormalities in patients with virilizing congenital adrenal hyperplasia. J Clin Endocrinol Metab 1978; 47: 1208-1215.

47. Bruining H, Bootsma AH, Koper JW, Bonjer J, de Jong FH, Lamberts SWJ. Fertility and body composition after laparoscopic bilateral adrenalectomy in a 30 -year-old female with congenital adrenal hyperplasia. J Clin Endocrinol Metab 2001; 86: 482-484.

48. Ehrmann DA, Barnes RB, Rosenfield RL. Polycystic ovary syndrome as a form of functional ovarian hyperandrogenism due to dysregulation of androgen secretion. Endocr Rev 1995; 16: 322-353.

49. Saygili F, Oge A, Yilmaz C. Hyperinsulinemia and insulin insensitivity in women with nonclassical congenital adrenal hyperplasia due to 21-hydroxylase deficiency: the relationship between serum leptin levels and chronic hyperinsulinemia. Horm Res 2005; 63: 270-274.

50. Charmandari E, Weise M, Bornstein SR, Eisenhofer G, Keil MF, Chrousos GP, Merke DP. Children with classic congenital adrenal hyperplasia have elevated serum leptin concentrations and insulin resistance: potential clinical implications. J Clin Endocrinol Metab 2002; 87: 2114-2120.

51. Barnes RB, Rosenfield RL, Ehrmann DA. Ovarian hyperandrogenism as a result of congenital adrenal virilizing disorders: evidence of perinatal masculinization of neuroendocrine function in women. J Clin Endocrinol Metab 1994; 79: 1328-1333.

52. Yarman S. Dursun A. Oguz F, Alagoel F. The prevalence, molecular analysis and HLA typing of late onset 21-hydroxylase deficiency in Turkish women with hirsutism and polycystic ovary. Endocr J 2004; 51: 31 36.

53. Kamel N, Tonyukuk V, Emral R., Copapcioglu D, Bastemir M, ' Guellue S. The prevalence of late onset congenital adrenal hyperplasia in hirsute women from central Anatolia. Endocr J 2003; 50: 815-823.

54. Kousta E, White DM, Cela E, McCarthy MI, Frabks S. The prevalence of polycystic ovaries in women with infertility. Hum Reprod 1999; 14: 2720-2723.

55. Jaaskelainen $J$, Tiitinen $A$, Voutilainen $R$ Sexual function and fertility in adult females and males with congenital adrenal hyperplasia. Horm Res 2001; 56: 7380.

56. Stikkelbroeck NMML, Hermus ARMM, Schouten D, Suliman HM, Jager GJ, Braat DDM, Otten BJ. Prevalence of ovarian adrenal rest tumours and polycystic ovaries in females with congenital adrenal hyperplasia: results of ultrasonography and MR imaging. Eur Radiol 2004; 14: 1802-1806.

57. Al-Ahmadie HA, Stanek J, Liu J, Mangu PN, Niemann T, Young RH. Ovarian 'tumour' of the adrenogenital syndrome - the first reported case. Am J Surg Pathol 2001; 25: 1443-1450.

58. Russo G, Paesano P, Taccagni G, Del Maschio A, Chiumello $\mathrm{G}$. Ovarian adrenal-like tissue in congenital adrenal hyperplasia [Letter]. N Engl J Med 1998; 339: 853-854.

59. Claahsen-van der Grinten HL, Hulsbergen-van de Kaa CA, Otten BJ. Ovarian adrenal rest tissue in congenital adrenal hyperplasia - a case report. J Pediatr Endocrinol Metab 2006; 19: 177-182.

60. Farkas A, Chertin B. Feminizing genitoplasty in patients with 46,XX congenital adrenal hyperplasia. J Pediatr Endocrinol Metab 2001; 14: 713-722.

61. Clayton PE, Miller WL, Oberfield SE, Ritzen EM, Sippell WG, Speiser PW. Consensus statement on 21hydroxylase deficiency from the European Society of Paediatric Endocrinology and the Lawson Wilkins Paediatric Endocrinology Society. Horm Res 2002; 58: 188.

62. Crouch NS, Minto CL, Laio LM, Woodhouse CRJ, Creighton SM. Genital sensation after feminizing genitoplasty for congenital adrenal hyperplasia: a pilot study. BJU Int 2004; 93: 135-138.

63. Eroglu E, Guendoglu G, Emir H, Ercan O, Soeylet Y, Danigmend $N$. Feminizing surgical management of intersex patients. Pediatr Surg Int 2004; 20: 543-547.

64. Al-Bassam A, Gado A. Feminizing genital reconstruction: experience with 52 cases of ambiguous genitalia. Eur J Pediatr Surg 2004; 14: 172-178.

65. Sotiropoulos A, Morishima A, Homsy Y, Lattimer JK. Long-term assessment of genital reconstruction in female pseudohermaphrodites. J Urol 1976; 115: 599-601.

66. Krege S, Walz KH, Hauffa BP, Koerner I, Ruebben H. Long-term follow-up of female patients with congenital adrenal hyperplasia from 21-hydroxylase deficiency, with special emphasis on the results of vaginoplasty. BJU Int 2000; 86: 253-259.

67. Slijper FM, Drop SLS, Molenaar JC, de Muinck KeizerSchrama SMPF. Long-term psychological evaluation of intersex children. Arch Sex Behav 1998; 27: 125-144.

68. Hines M, Brook C, Conway GS. Androgen and psychosexual development: core gender identity, sexual orientation and recalled childhood gender role behaviour in women and men with congenital adrenal hyperplasia. J Sex Res 2004; 41: 75-81.

69. Meyer-Bahlburg HFL. What causes low rates of childbearing in congenital adrenal hyperplasia? J Clin Endocrinol Metab 1999; 84: 1844-1847.

70. Wisniewski AB, Mignon CJ, Malouf MA, Gearhart JP. Psychosexual outcome in women affected by congenital adrenal hyperplasia due to 21-hydroxylase deficiency. J Urol 2004; 171: 2497-2501.

71. Noordenstrom A, Servin A, Bohlin G, Larsson A, Wedell A. Sex-typed toy play behaviour correlates with the degree of prenatal androgen exposure assessed by CYP21 genotype in girls with congenital adrenal hyperplasia. J Clin Endocrinol Metab 2002; 87: 5119-5124. 
72. Hall CM, Jones JA, Meyer-Bahlburg HFL, Dolezal C, Coleman M, Foster P, Price DA, Clayton PA. Behavioral and physical masculinization are related to genotype in girls with congenital adrenal hyperplasia. J Clin Endocrinol Metab 2004; 89: 419-424.

73. Berenbaum SA, Bailey JM. Effects on gender identity of prenatal androgens and genital appearance: evidence from girls with congenital adrenal hyperplasia. J Clin Endocrinol Metab 2003; 88: 1102-1106.
74. Brook HM, Conway GS. Androgen and psychosexual development: core gender identity, sexual orientation and recalled childhood gender role behaviour in women and men with congenital adrenal hyperplasia. J Sex Res 2004; 41 : 75-81.

75. Long DN, Wisniewsky AB, Migeon CJ. Gender role across development in adult women with congenital adrenal hyperplasia due to 21-hydroxylase deficiency. J Pediatr Endocrinol Metab 2004; 17: 1357-1373. 
Brought to you by | Radboud University Nijmegen (Radboud University Nijmegen)

Authenticated | 172.16.1.226

Download Date | 7/12/12 5:04 PM 